\title{
Laser Powder Bed Fusion of a High Strength Al-Si-Zn-Mg-Cu Alloy
}

\author{
Alberta Aversa ${ }^{1, *(10)}$, Giulio Marchese ${ }^{1}$ (D), Diego Manfredi ${ }^{2}$ (1), Massimo Lorusso ${ }^{2}$, \\ Flaviana Calignano $^{3}$, Sara Biamino ${ }^{1,2}$ (D), Mariangela Lombardi ${ }^{1,2}$ (D), Paolo Fino ${ }^{1}$ \\ and Matteo Pavese ${ }^{1}$ \\ 1 Department of Applied Science and Technology, Politecnico di Torino, Corso Duca degli Abruzzi 24, \\ 10129 Torino, Italy; giulio.marchese@polito.it (G.M.); sara.biamino@polito.it (S.B.); \\ mariangela.lombardi@polito.it (Mar.L.); paolo.fino@polito.it (P.F.); matteo.pavese@polito.it (M.P.) \\ 2 Center for Sustainable Futures Technologies-CSFT@POLITO, Istituto Italiano di Tecnologia, Corso Trento 21, \\ 10129 Torino, Italy; diego.manfredi@iit.it (D.M.); massimo.lorusso@iit.it (Mas.L.) \\ 3 Department of Management and Production Engineering (DIGEP), Politecnico di Torino, \\ Corso Duca degli Abruzzi 24, 10129 Torino, Italy; flaviana.calignano@polito.it \\ * Correspondence: alberta.aversa@polito.it; Tel.: +39-011-090-4763
}

Received: 14 March 2018; Accepted: 24 April 2018; Published: 26 April 2018

\begin{abstract}
Al-Si-Zn-Mg-Cu samples were produced using Laser Powder Bed Fusion from mixed AlSi10Mg and 7075 powders. It was observed that the introduction of silicon to an Al- $\mathrm{Zn}-\mathrm{Mg}-\mathrm{Cu}$ alloy strongly reduced the crack density, probably because of the reduction of the solidification range, the improved fluidity of the molten phase and the reduction of the coefficient of thermal expansion. The density measurements showed that crack-free samples can be successfully produced with this powder mixture. The obtained Al-Si-Zn-Mg-Cu samples were characterized in terms of microstructure, hardness and tensile properties showing that this composition is very promising for future powder bed additive manufacturing processes.
\end{abstract}

Keywords: Laser Powder Bed Fusion (LPBF); Additive Manufacturing (AM); 7075 aluminum alloy; high strength; mechanical properties

\section{Introduction}

Laser Powder Bed Fusion (LPBF) is a powder bed Additive Manufacturing (AM) process that enables the production of metal components by means of a layer-by-layer process. This technology has been found to be very attractive for some alloys such as titanium and nickel based alloys due to its ability to produce near net shape components and hence to reduce the amount of material used and the post processing phases needed for conventional production techniques [1,2]. The production of aluminum parts by laser-based AM faces many challenges because of the high reflectivity and thermal conductivity of aluminum. This leads to the necessity for high power levels in order to melt the scan tracks. Moreover, aluminum powders are generally characterized by a limited flowability that may produce non-homogeneous powder beds and lead to the formation of pores within the parts [3]. Furthermore, some high strength aluminum alloys contain highly volatile elements, such as $\mathrm{Zn}$ and $\mathrm{Mg}$, and these are particularly critical for AM technologies because of the extremely high temperatures of the melt pool [4]. Recently, many studies have been carried out on the production of aluminum alloys by LPBF techniques. Al-Si alloys and, in particular, AlSi10Mg have been shown to be very suitable for AM technologies [5]. This casting alloy, with a near eutectic composition, has in fact a narrow solidification range and a good fluidity in the molten state. These characteristics allow the AM production of fully dense metal parts $[6,7]$. 
Despite this growing interest in the AM processability of Al-Si alloys, to date, to the best of our knowledge, only a few studies have been published on the AM process of high strength aluminum alloys. It is well known that the alloys belonging to the 7xxx series are suitable for many applications in aerospace industries as they are characterized by high specific strength and toughness achieved mainly through the precipitation of the $\mathrm{MgZn}_{2}$ phase. However, these alloys are not weldable because they suffer strongly from liquation cracking. Notwithstanding this, because of the strong industrial interest in the AM processability of these alloys, in recent years, some studies have focused on the microstructural characterization of AM 7075 samples. Li et al., for example, studied the processability of a 7075 alloy by means of the drop-on-demand (DOD) method [8]. They focused on drop cooling rate and morphology, however, no consideration on cracks was reported. Kaufmann et al. studied the LPBF processing of a 7075 alloy and showed that, because of the rapid cooling that arises during the laser scanning, with the fixed parameters, the samples were characterized by hot cracks oriented along the building direction [9]. Furthermore, in their study, they investigated the chemical composition of the LPBF samples and observed that a significant quantity of zinc evaporates as a consequence of the extremely high temperatures of the melt pool. The reduction in the zinc content was also observed by Qi et al. who investigated the cracking phenomena during the LPBF process of the 7075 alloy [10]. They found that three types of cracks, all oriented along the grain boundaries, form during the LPBF process of this alloy. Furthermore, the crack density was correlated to the melting mode that arises during the laser scanning: the lowest crack density was observed when the keyhole melting mode arose due to the solidification of fine and irregular grains.

Recently, different studies have focused on the modification of the 7075 chemical composition, in order to make it processable by AM technologies. Montero Sistiaga et al. for example, studied the processability of a Si-modified 7075 by LPBF and pointed out that the introduction of Si particles strongly decreases the crack formation during LPBF due to the improved fluidity of the molten phase and the reduction of both the melting range and the coefficient of thermal expansion [11]. The authors also investigated the effect of the heat treatment on hardness; with the most suitable heat treatment, it was possible to achieve a hardness value of $171 \mathrm{HV}$. However, clarification on the Si distribution within the LPBF samples was not carried out. The distribution of $S i$ in these samples might be very critical; previous studies have demonstrated in fact that the use of pure metallic particles for the in-situ formation of an alloy may cause a non-homogeneous composition within the samples [12,13]. Finally, Martin et al. obtained crack free LPBF 7075 parts by adding hydrogen stabilized Zr nanoparticles to the 7075 powder [14]. The introduction of these particles allowed the precipitation of the $\mathrm{Al}_{3} \mathrm{Zr}$ phase which is strongly coherent with the $\mathrm{Al}$ structure. These coherent precipitates resulted in a heterogeneous nucleation, fine grain sizes and therefore crack free samples.

In the present work, a different method to modify the composition of a 7075 powder for LPBF was investigated. The 7075 powder was mixed with an AlSi10Mg powder in order to increase the Si content. The microstructure and the mechanical properties of LPBF samples with this new Al-Si-Zn-Mg-Cu were studied and reported below.

\section{Materials and Methods}

Gas atomized 7075 and AlSi10Mg powders provided by LPW Technology Ltd. (Cheshire, UK) and EOS GmbH (Krailling, Germany), respectively, were used. The Field Emission Scanning Electron Microscopy (FE-SEM) images, reported in Figure 1, reveal that the 7075 batch contains many particles characterized by an irregular shape; in the AlSi10Mg powder, most of the particles have a spherical shape. Furthermore, the AISi10Mg batch contains some finer particles and some satellites with respect to the 7075 one (Figure $1 b$ ).

A mixed powder batch was prepared by dry mixing AlSi10Mg with 7075 powders in ceramic jars for $24 \mathrm{~h}$ without any grinding medium in order to avoid the damage of the particles. The rotational speed of the system was fixed at $60 \mathrm{rpm}$. This mixing method was used because in previous works it was demonstrated not to damage the particles shape $[15,16]$. The flow behavior of the commercial and 
mixed powders was evaluated by the tap density measurements in order to assess the effect of different particles morphology on the powder flowability. The Hausner Ratio (HR) values were calculated as the ratio of tap density $\left(\rho_{\text {tap }}\right)$ and loose poured bulk density $\left(\rho_{\text {bulk }}\right)$.
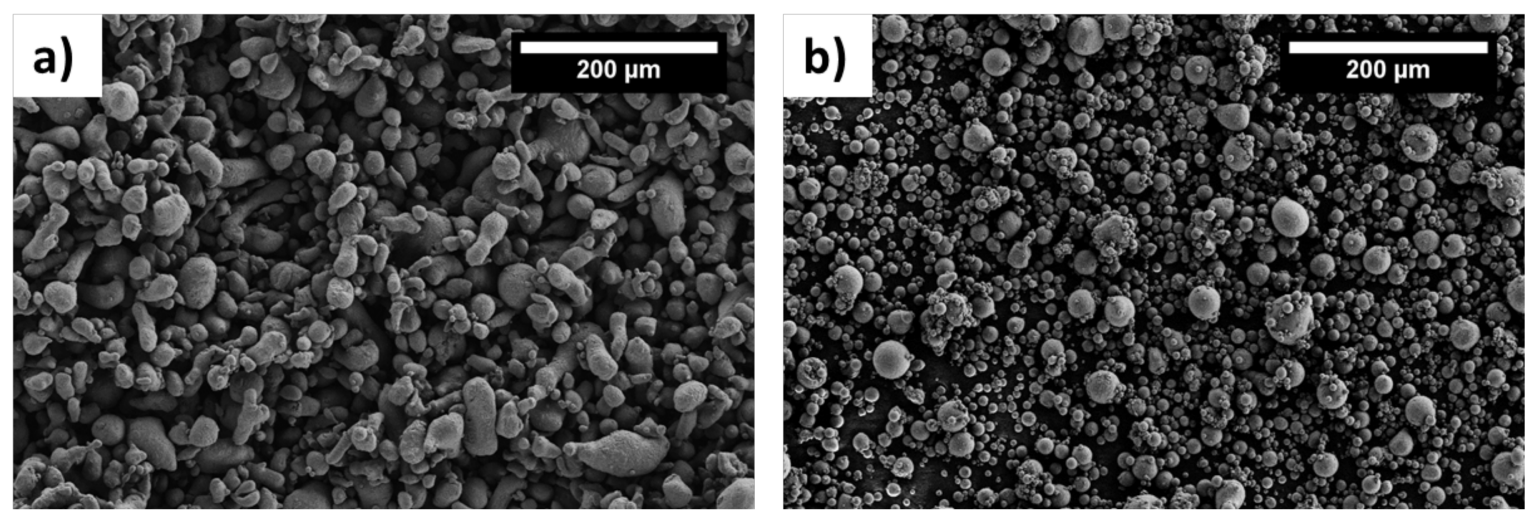

Figure 1. Field Emission Scanning Electron Microscopy (FE-SEM) micrographs of (a) 7075 and (b) AlSi10Mg powders.

The mean nominal composition of the mixed powder batch (50\% 7075), selected on the basis of the results of a previous work [17], is reported, together with the composition of AlSi10Mg and 7075, in Table 1.

Table 1. Nominal chemical composition of the powders.

\begin{tabular}{cccccccccc}
\hline Weight \% & $\mathbf{S i}$ & $\mathbf{F e}$ & $\mathbf{C u}$ & $\mathbf{M n}$ & $\mathbf{M g}$ & $\mathbf{C r}$ & $\mathbf{Z n}$ & $\mathbf{T i}$ & $\mathbf{A l}$ \\
\hline 7075 & $<0.40$ & $<0.50$ & $1.2-2.0$ & $<0.3$ & $2.1-2.9$ & $0.18-0.25$ & $5.1-6.1$ & $<0.2$ & Bal. \\
AlSi10Mg & $9.0-11.0$ & $<0.55$ & $<0.05$ & $<0.45$ & $0.2-0.45$ & - & $<0.10$ & $<0.15$ & Bal. \\
$50 \% 7075 *$ & $4.7-5.5$ & $<0.50$ & $0.6-1.0$ & $<0.38$ & $1.15-1.7$ & $0.09-0.13$ & $2.5-3.1$ & $<0.17$ & Bal. \\
\hline
\end{tabular}

* Calculated starting from the commercial powder composition.

An EOS M270 Dual Mode system was used to build all the samples. This machine uses an $\mathrm{Yb}$ fiber laser with a power up to $200 \mathrm{~W}$ and a scan speed up to $7000 \mathrm{~mm} / \mathrm{s}$; the whole process is carried out in Ar atmosphere on a heatable platform.

Cubic samples $(10 \times 10 \times 10 \mathrm{~mm})$ were built on $100{ }^{\circ} \mathrm{C}$ heated platform with the mixed powder batch varying the main building parameters such as power $(P)$, scan speed $(v)$, hatching distance $\left(h_{d}\right)$. All samples were built using $30 \mu \mathrm{m}$ as layer thickness $(t)$ and the rotated EOS scanning strategy [18].

The overall effect of the building parameters on the porosity was studied by the Volumetric Energy Density (VED) parameter which obeys to the following equation:

$$
V E D=\frac{P}{v h_{d} t}
$$

The building parameters used for the process optimization were varied in the ranges reported in Table 2.

Table 2. Ranges of building parameters used for cubes.

\begin{tabular}{cccc}
\hline Parameters & Power $(\mathbf{W})$ & Scan Speed $(\mathbf{m m} / \mathbf{s})$ & Hatching Distance $(\mathbf{m m})$ \\
\hline Min. value & 180 & 400 & 0.15 \\
Max. value & 195 & 800 & 0.17 \\
\hline
\end{tabular}


After a coarse polishing, in order to remove the surface roughness, the porosity values were evaluated by the Archimede's method. Based on the porosity values, optimized building parameters, that allow the production of dense samples, were selected among the parameters tested. The densest cubic samples were cut along the building direction, polished and etched for $10 \mathrm{~s}$ with a Keller solution in order to observe the microstructure. Energy Dispersive X-ray spectroscopy (EDX) analyses were carried out using a Phenon XL Scannin Electron Microscope (SEM) (Phenom-World BV, Eindhoven, The Netherlands) equipped with and EDX detector on sample cross sections in order to see whether the flows that arise in the melt pool, due to the Marangoni effect and the recoil pressure, allow the production of a homogeneous alloy throughout the samples $[19,20]$.

Sample hardness was measured by means of Brinell hardness tests, using a $2.5 \mathrm{~mm}$ tungsten carbide ball and applying $62.5 \mathrm{~kg}$. Micro-hardness was also measured using a Leica micro-hardness Tester VMHT (Leica, Wetzlar, Germany.) with a load of $100 \mathrm{~g}$ applied for $15 \mathrm{~s}$. In both cases, the average hardness values were determined from five indentations on the $X-Z$ cross section of each sample. Samples made with the optimized parameters underwent different direct ageing treatments and were characterized in terms of hardness and microstructure. In particular, as ageing temperatures 170, 160 and $150{ }^{\circ} \mathrm{C}$ were selected based on the 7075 alloy standard ageing treatments present in the literature for alloys with similar compositions [21,22]. Furthermore, some samples underwent the stress relieving heat treatment at $300{ }^{\circ} \mathrm{C}$ for $2 \mathrm{~h}$, in order to have a more complete comparison with the AlSi10Mg mechanical properties.

$\mathrm{X}$-ray analyses were carried out on the $\mathrm{X}-\mathrm{Z}$ cross section of the as-built and heat treated samples in order to analyze the precipitates that forms during the LPBF process and the above mentioned stress relieving heat treatment.

Samples in the as built and heat treated conditions were cut, polished and etched with a Keller's reagent for $10 \mathrm{~s}$. The samples' cross sections were then observed by optical and FE-SEM microscopy (Zeiss Merlin, Zeiss, Oberkochen, Germany).

Finally, flat tensile samples with $4 \mathrm{~mm}$ thickness, $6 \mathrm{~mm}$ width and $25 \mathrm{~mm}$ gage length were built with the optimized parameters parallel to the building platform with volume type support structures, removed from the building platform with EDM and then shot peened and tested according to the ASTM E8M. The tensile tests were performed with a Zwick Z100 tensile machine (Zwick Roell, Ulma, Germany) connected to a contact extensometer and using $8 \times 10^{-3} \mathrm{~s}^{-1}$ as strain rate on as-built and heat treated 50\% 7075 samples and on AlSi10Mg samples built with the AlSi10Mg standard parameters $\left(P=195 \mathrm{~W}, v=800 \mathrm{~mm} / \mathrm{s}, h_{d}=0.17 \mathrm{~mm}\right)$.

\section{Results}

At first, the effect of the mixing method on the powder quality was evaluated by tap density measurements. The HR values of AlSi10Mg, 7075 and $50 \% 7075$ powder batches were 1.27, 1.22 and 1.25 respectively. These values are in the ranges generally referred to as "Fair/Passable". It can be noted that, despite its spherical shape, the AlSi10Mg powder is characterized by a slightly worst flow behavior with respect to the 7075. The mixed powder batch has an intermediate HR value and can be therefore used for the LPBF process.

Samples built with 7075 powder and the $50 \% 7075$ powder batch were built; the optical micrographs of two samples' cross section clearly show the advantages of the introduction of $\mathrm{Si}$ to the 7075 alloy (Figure 2). It is clear in fact that in the LPBF 7075 sample a strong liquation cracking phenomenon arises (Figure 2a). This cracking phenomenon is due to the presence of a thin liquid film at the grain boundaries that cannot follow the shrinkage due the solidification. Based on these considerations, it is evident that a narrow solidification range, a high fluidity of the molten phase, a low coefficient of thermal expansion (CTE) and a reduced solidification shrinkage may reduce this cracking phenomenon. In agreement with literature, in LPBF samples, 7075 cracks are oriented along the building direction. Previous works demonstrated that the cracks that generate during the laser scanning are oriented along the building direction as they follow the columnar grain boundaries $[10,14]$. The comparison 
of (Figure 2a,b) clearly demonstrates that the introduction of silicon to the 7075 composition strongly reduces the crack density of the samples. The reduction of the crack density can be therefore ascribed to the narrower solidification range of the alloy, to the lower coefficient of thermal expansion (CTE) value and to its improved fluidity [11].
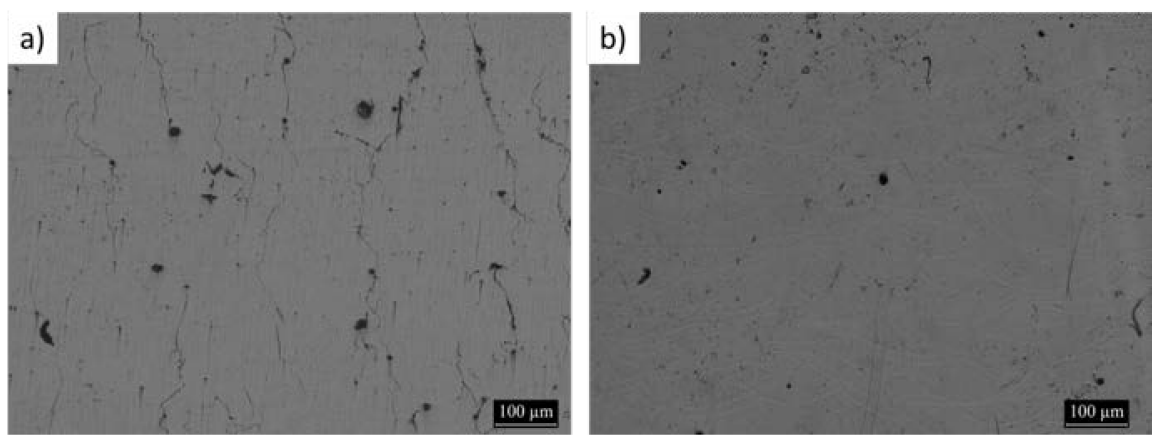

Figure 2. Optical micrographs of (a) 7075 alloy and (b) 50\% 7075 alloy built with not optimized process parameters $\left(P=195 \mathrm{~W}, v=600 \mathrm{~mm} / \mathrm{s}\right.$ and $\left.h_{d}=0.17 \mathrm{~mm}\right)$.

The densities of the 50\% 7075 samples built were firstly evaluated by the Archimede's method. It must be pointed out that this method was valid as the porosity was not interconnected.

From the porosity versus VED graph of the $50 \% 7075$ reported in Figure 3 it can be noted that dense samples can be easily produced and that this alloy mainly follows the typical trend observed in most of the alloys processed by LPBF; the higher is the energy density the lower is the porosity [23]. Based on this graph, the parameters corresponding to the arrow $\left(P=195 \mathrm{~W}, v=600 \mathrm{~mm} / \mathrm{s}\right.$ and $\left.h_{d}=0.15 \mathrm{~mm}\right)$ were selected as the optimized ones for this new alloy. These parameters are characterized by a slightly higher VED with respect to the EOS standard parameters for aluminum; this might be due the lower Si content of this alloy, with respect to the AlSi10Mg, that causes a lower laser absorption and lower fluidity of the molten phase.

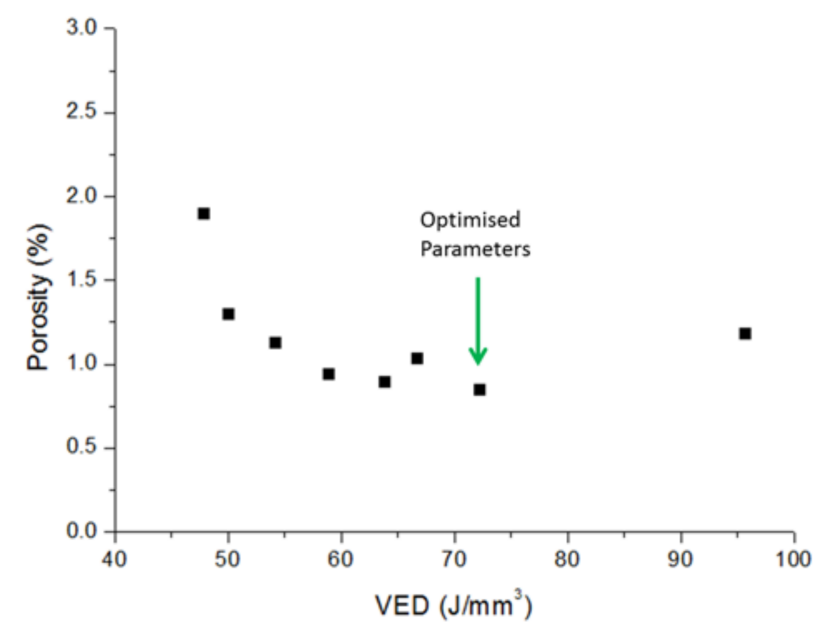

Figure 3. Porosity versus Volumetric Energy Density (VED) graph of 50\% 7075 Laser Powder Bed Fusion (LPBF) samples.

The porosity values reported in Figure 3 were compared with image analyses data, obtained with the ImageJ software (version: v1.51J8, National Institutes of Health, Bethesda, MD, USA) on eight $50 \times$ images taken on each sample cross section. Similar results were obtained, in particular the porosity of the samples built with the optimized parameters was calculated to be $1.1 \%$. 
In order to assess the homogeneity of LPBF parts produced from mixed powders, EDX measurements were carried out on the cross section of samples built with the optimized parameters. The EDX lines revealed that a homogeneous distribution of the reinforcing elements throughout the melt pool can be achieved (Figure 4). The thermophysical phenomena that arise in the melt pool produce the homogeneous dispersion of most of the alloying elements and therefore the formation of the $50 \%$ 7075 alloy starting from AlSi10Mg + 7075 powder mixture. However, it must be pointed out that the chemical composition of the alloy measured with EDX analyses revealed that, because of the high temperatures reached in the melt pool, part of the Zn evaporates (Table 3).

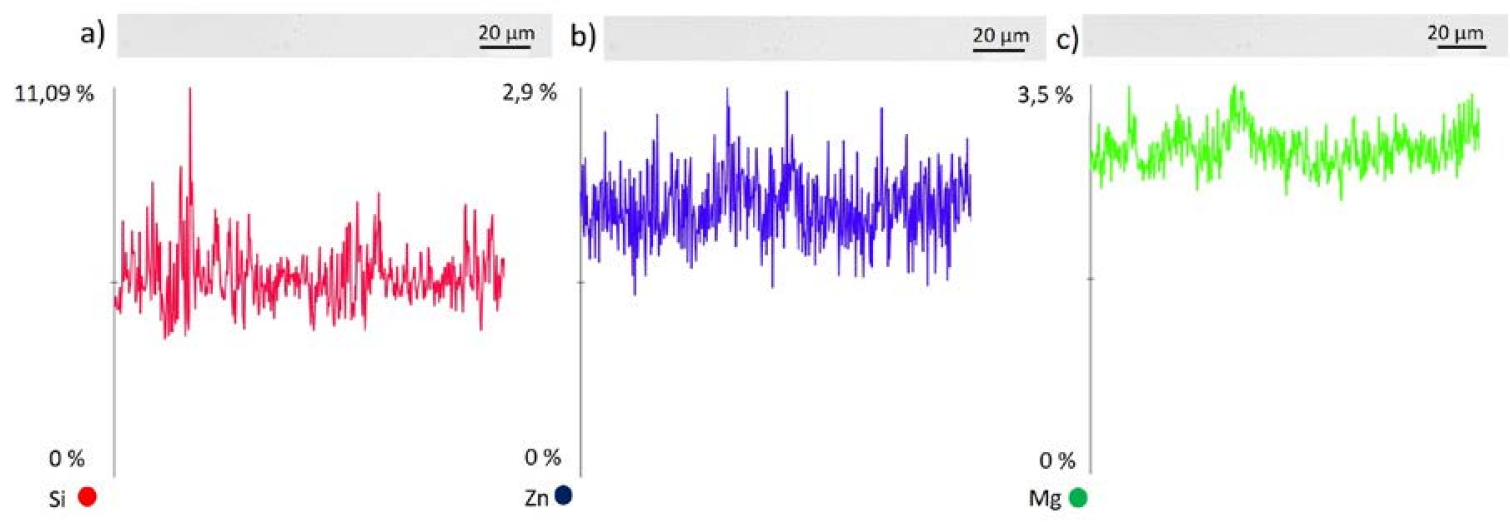

Figure 4. Energy Dispersive X-ray spectroscopy (EDX) lines of (a) $\mathrm{Si}$ (b) Zn and (c) Mg.

Table 3. Measured and nominal composition of a 50\% 7075 sample built with the optimized parameters.

\begin{tabular}{cccccccccc}
\hline Weight $\%$ & $\mathbf{S i}$ & $\mathbf{F e}$ & $\mathbf{C u}$ & $\mathbf{M n}$ & $\mathbf{M g}$ & $\mathbf{C r}$ & $\mathbf{Z n}$ & $\mathbf{T i}$ & $\mathbf{A l}$ \\
\hline Measured & 5.3 & - & 0.8 & - & 1.6 & - & 2.02 & - & Bal. \\
Nominal & $4.7-5.5$ & $<0.5$ & $0.6-1.0$ & $<0.38$ & $1.15-1.7$ & $0.09-0.13$ & $2.5-3.1$ & $<0.17$ & Bal. \\
\hline
\end{tabular}

The optical micrographs of 50\% 7075 etched samples, reported in Figure 5, reveal that their microstructure is constituted by the interconnection of multiple melt pools as in the case of the AlSi10Mg samples [5]. A sample was built without the rotating scanning strategy in order to analyze the shape of the melt pools for this alloy (Figure 5a). The comparison of this image with a micrograph of a sample built with the rotation (Figure $5 b$ ) clearly shows the advantages that the scanning strategy brings to the densification. The samples built without the $67^{\circ}$ rotated scanning strategy is characterized by irregular pores that suggest a poor melt pool interconnection due to a repetitive scanning strategy. Furthermore, Figure 5b,c shows that the melt pools are characterized by areas with different cells size and shape. The melt pool center contains fine and equiaxed cells while elongated cells are present at the melt pool boundaries.

FE-SEM images of the as-built 50\% 7075 alloy reported in Figure 6 confirm that the microstructure is similar to the as-built AlSi10Mg one and is constituted by fine $\alpha$-Al cells (dark grey) surrounded by the eutectic network (bright grey). Similar cellular microstructures were observed by Wu et al. who deeply investigated the complex formation mechanism of Al cells during the LPBF process of AlSi10Mg [24]. However, in the 50\% 7075 case, the eutectic network results to be less continuous with respect to the AlSi10Mg one [5,25].

Since previous works suggested that LPBF aluminum alloys in the as-built state can be considered as supersaturated solid solutions [26,27], the effect of a direct ageing on the phase composition and the mechanical properties was investigated by XRD measurements, hardness and tensile tests. Figure 7 reports the Brinell hardness trend with the ageing time of 50\% 7075 LPBF samples and clearly shows that the direct ageing strongly increases the mechanical properties of this alloy, suggesting that some precipitation arises. The highest hardness values were achieved by ageing the samples for $6 \mathrm{~h}$ at $160{ }^{\circ} \mathrm{C}$. 
The Brinell hardness value of the stress relived 50\% 7075 was $65.0 \mathrm{HB}$ and has not been reported in the graph.
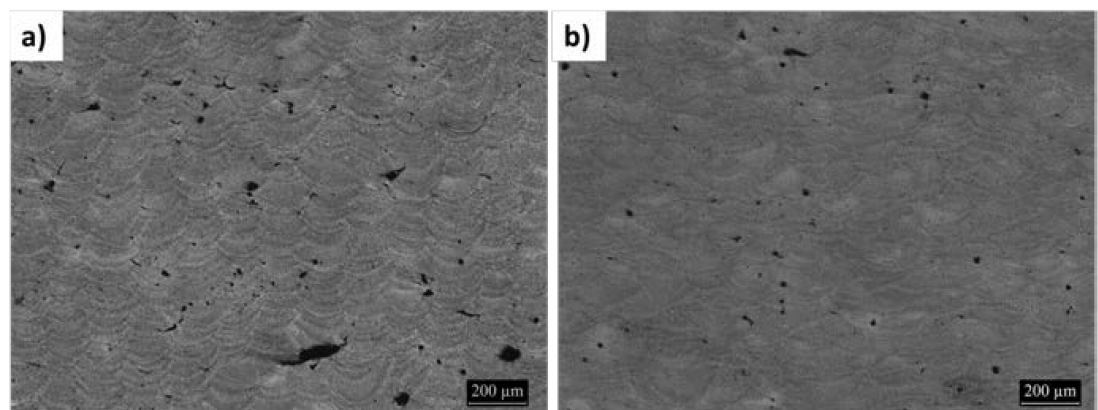

\section{c)}

d)
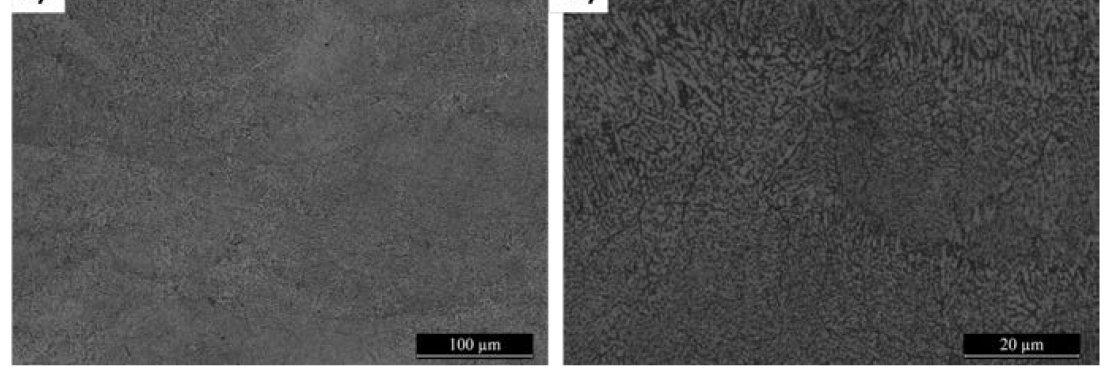

Figure 5. Optical micrographs of 50\% 7075 etched samples built (a) without the $67^{\circ}$ rotating scanning strategy; (b-d) with the rotating scanning strategy and the optimized parameters.
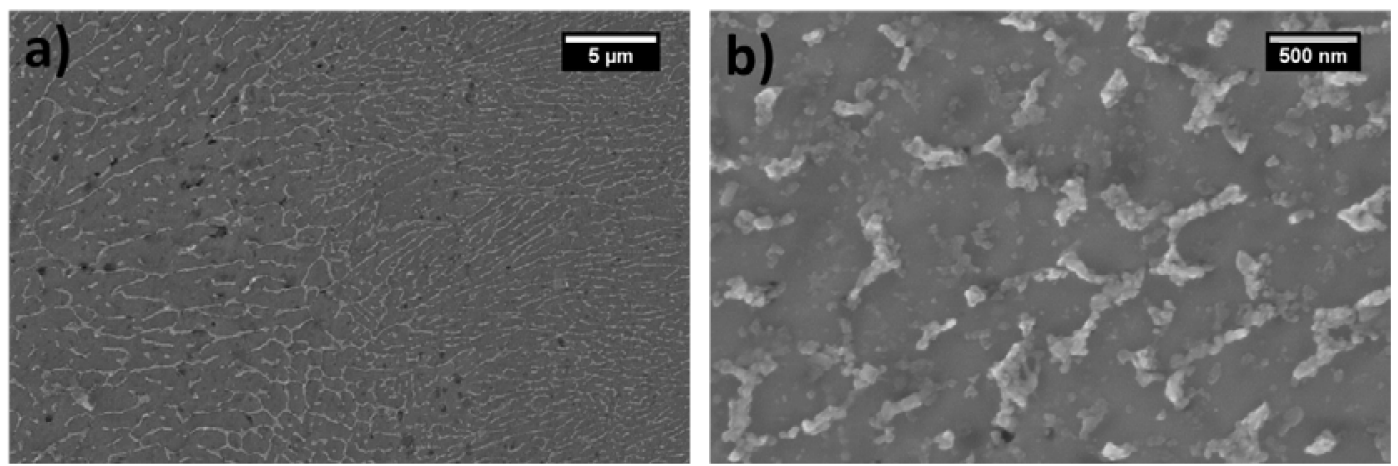

Figure 6. FE-SEM micrographs of 50\% 7075 built with the optimized parameters.

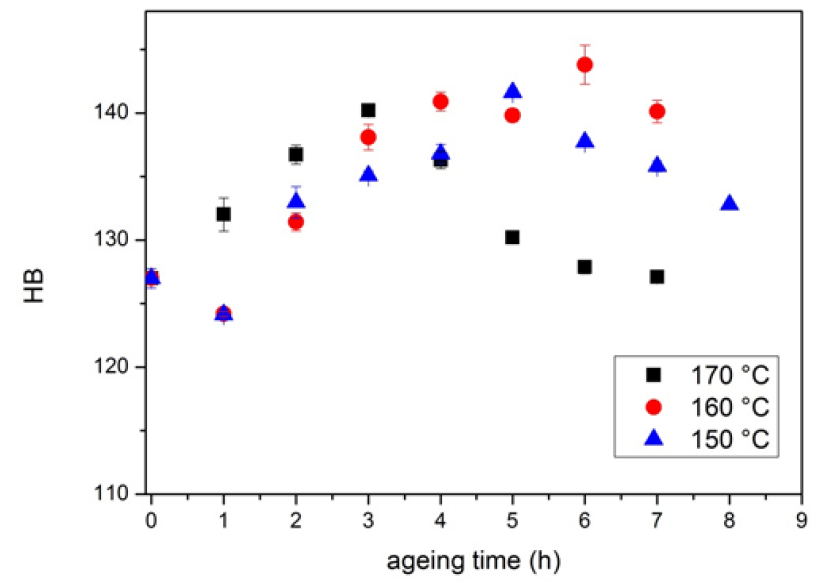

Figure 7. Brinell hardness as a function of the ageing time. 
The XRD patterns of 50\% 7075 sample in different conditions, reported in Figure 8, confirm that this alloy in the as-built state is mainly constituted by $\mathrm{Al}$ and reveal that the stress relieving and the ageing heat treatments favor the precipitation of silicon and some intermetallic phase (Figure $8 \mathrm{~b}$ ). It must be pointed out that, notwithstanding the longer heat treatment time, because of the lower temperature, a smaller precipitation arises during samples' ageing than during stress relieving. The intermetallic peaks that were also identified in the pattern of the as-built sample suggest that part of the alloying elements precipitates during the building process.
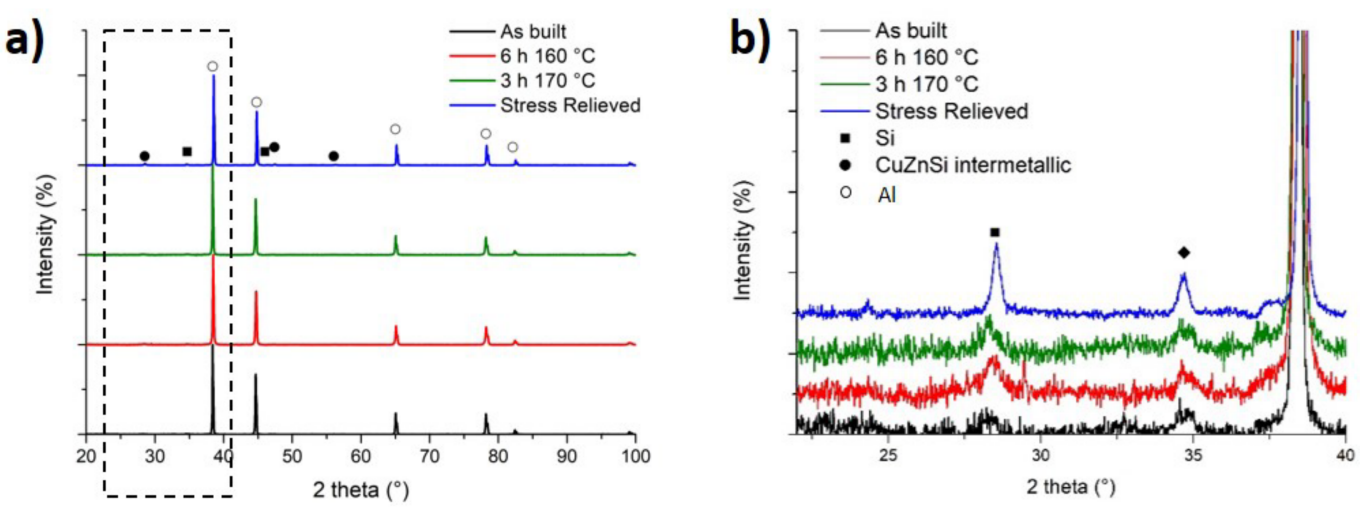

Figure 8. (a) XRD patterns of 50\% 7075 alloys in the as built state and after different heat treatments and (b) magnification in the range of $22-42^{\circ}$.

The precipitation of some intermetallic phase during ageing was confirmed by the comparison FE-SEM micrographs of aged samples (Figure 9) with the as-built ones (Figure 6). After the heat treatment, in fact, some bright phases can be recognized within the $\mathrm{Al}$ cells. No clear difference could be observed between the microstructures of samples aged in different conditions (Figure 9a,b).
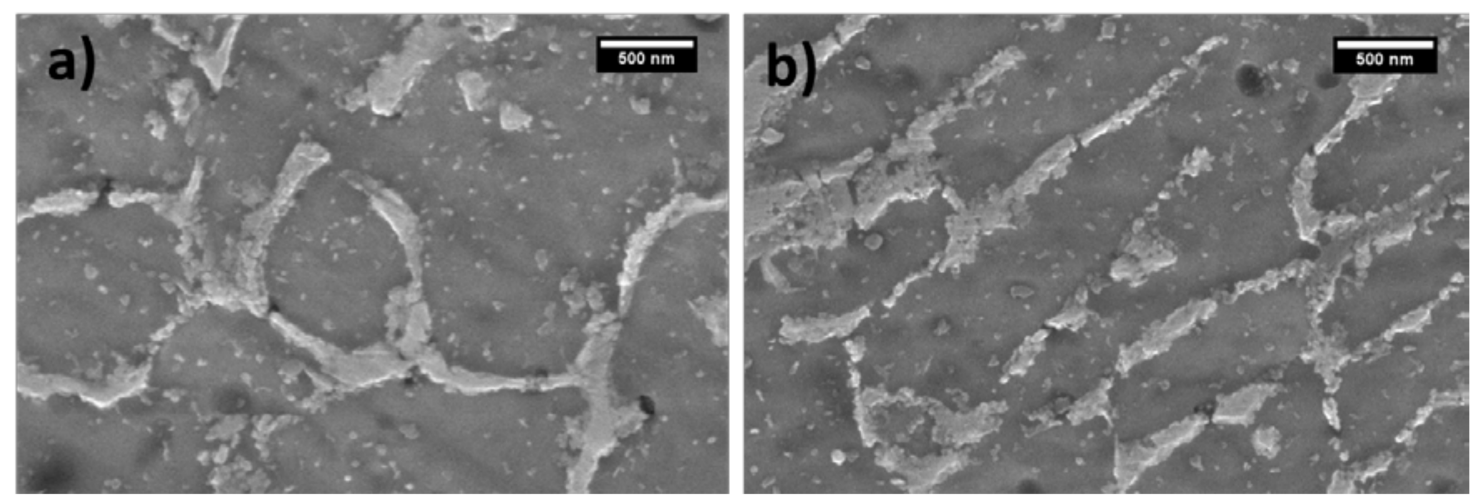

Figure 9. FE-SEM micrographs of 50\% 7075 built with the optimized parameters aged for (a) $3 \mathrm{~h}$ at $170{ }^{\circ} \mathrm{C}$ and (b) for $6 \mathrm{~h}$ at $160{ }^{\circ} \mathrm{C}$.

Tensile tests were carried out on 50\% 7075 in the as-built state and aged with two ageing treatments. The tensile properties and the most representative tensile curves of the alloys are reported in Table 4 and Figure 10 and compared with the curve of an as-built AlSi10Mg sample built with its standard parameters. It is evident that the 50\% 7075 composition seems very promising for the LPBF process. This alloy in the as built state has in fact $25 \%$ and $7 \%$ higher yield $\left(\sigma_{y}\right)$ and ultimate tensile (UTS) strengths, respectively, with respect to the as built AlSi10Mg. Furthermore, as expected, the direct ageing treatment allows a further $11 \%$ increase in $\sigma_{y}$ due to the precipitation of intermetallic phases. The highest mechanical properties, $\sigma_{y}=350.6 \mathrm{MPa}$ and $U T S=415.1 \mathrm{MPa}$, were achieved by ageing the samples at $160^{\circ} \mathrm{C}$ for $6 \mathrm{~h}$. 
Table 4. Tensile properties of the 50\% 7075 samples in different ageing condition compared to the AlSi10Mg ones in the as built state, tested just after shot peening.

\begin{tabular}{cccc}
\hline Alloys & $\sigma_{y}$ (MPa) & UTS (MPa) & $\varepsilon_{r}(\%)$ \\
\hline $50 \% 7075$ As built & 315 & 387 & 2.7 \\
$50 \% 70753$ h $170{ }^{\circ} \mathrm{C}$ & 315 & 370 & 2.1 \\
$50 \% 70756$ h $160^{\circ} \mathrm{C}$ & 350 & 415 & 2.3 \\
AlSi10Mg As built & 250 & 362 & 3.3 \\
\hline
\end{tabular}

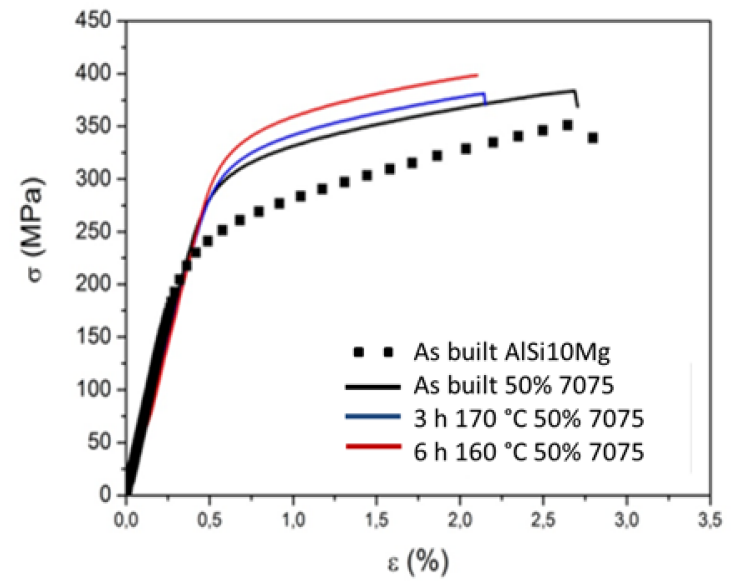

Figure 10. Tensile curves of 50\% 7075 samples in the as-built state and aged in different conditions compared with the AlSi10Mg one in the as-built state.

The hardness values and the tensile strengths of the 50\% 7075 alloy measured in different conditions are compared in Table 5 with literature data of alloys with similar compositions. It is evident that the hardness of $50 \% 7075$ in the as-built state is slightly lower with respect to the AlSi10Mg one [12]. Notwithstanding this, the $50 \% 7075$ is characterized by higher tensile properties and in particular higher yield strength than the AlSi10Mg. Furthermore, it must be noted that the hardness and the tensile properties of 50\% 7075 increase after the ageing treatment and reaches values that are lower than the 7075 but comparable with other high strength 7xxx alloys (e.g., hardness of 7050). Besides, it must be mentioned that the stress relieving heat treatment $\left(300^{\circ} \mathrm{C}\right.$ for $\left.2 \mathrm{~h}\right)$, generally used for LPBF AlSi10Mg parts, is not suitable for this composition as it strongly reduces samples' hardness. This reduction in hardness is mainly due to the growth of the microstructure and to the over ageing caused by high temperature involved in the stress relieving heat treatment.

Table 5. Hardness values of 50\% 7075 samples built with the optimized parameters compared with literature data related to other $\mathrm{Al}$ alloys.

\begin{tabular}{|c|c|c|c|c|c|}
\hline Material & Process & $H B$ & $H V$ & $\sigma_{y}(\mathbf{M P a})$ & UTS (MPa) \\
\hline AlSi10Mg [12] & LPBF & 128.6 & 135.3 & 250 & 362 \\
\hline $50 \% 7075$ & LPBF & 126.9 & 135.8 & 315 & 387 \\
\hline $50 \% 7075$ & LPBF stress relieved & 65.0 & 73.4 & - & - \\
\hline $50 \% 7075$ & LPBF 3 h $170{ }^{\circ} \mathrm{C}$ & 140.2 & 148.8 & 315 & 370 \\
\hline $50 \% 7075$ & $\mathrm{LPBF} 6 \mathrm{~h} 160^{\circ} \mathrm{C}$ & 143.8 & 152.9 & 350 & 415 \\
\hline $7075[11,21]$ & Extruded and T6 & $165-169$ & 175.0 & 406 & 582 \\
\hline $7050[21]$ & Cold rolled and T6 & $150-155$ & - & 430 & 606 \\
\hline $4 \%$ Si modified 7075 [11] & LPBF & - & 160.0 & - & - \\
\hline $4 \%$ Si modified 7075 [11] & $\mathrm{LPBF}$ and aged $\left(150^{\circ} \mathrm{C} 6 \mathrm{~h}\right)$ & - & 171.0 & - & - \\
\hline 7075 + Zr [14] & LPBF and aged & - & $\sim 130-140$ & - & - \\
\hline
\end{tabular}


Finally, the comparison of the $50 \% 7075$ properties with literature data shows that it was not possible to achieve the T6 7075 tensile properties. However, with respect to new alloys for AM processes, the $50 \% 7075$ values have similar or higher hardness values.

\section{Conclusions}

In this work the properties of a new aluminum alloy were investigated. The main results can be summarized as follows:

- $\quad$ The introduction of silicon in the 7075 alloy strongly reduces the solidification cracking probably by reducing the solidification range and the coefficient of thermal expansion.

- EDX analyses revealed that it is possible to obtain samples with a homogenous composition starting from mixed powders. The reinforcing elements are in fact distributed thanks to the Marangoni flow and the recoil pressure phenomenon that arise in the melt pool.

- $\quad$ The hardness tests revealed that it is possible to increase the mechanical properties of as built LPBF samples by the selection of an optimized ageing heat treatment.

- $\quad$ The tensile tests performed on the as-built and aged samples confirmed that the $50 \% 7075$ samples are characterized by higher mechanical properties than AlSi10Mg and revealed that the ageing heat treatment allows a further increase in both yield and ultimate tensile strength.

Author Contributions: A.A. and M.P. conceived the study, A.A. made the basic characterization and wrote the paper, G.M. performed FE-SEM analyses; D.M. and F.C. supported the samples design and production, Mas.L. performed tensile tests, S.B. performed the XRD measurements; Mar.L., M.P. and P.F. supervised the whole work and revised the manuscript.

Funding: This research was funded by the European project AMAZE, Additive Manufacturing Aiming toward Zero Waste and Efficient Production of High-Tech Metal Products grant number [313781].

Acknowledgments: The authors would like to acknowledge the European research project belonging to the VII framework program AMAZE, Additive Manufacturing Aiming toward Zero Waste and Efficient Production of High-Tech Metal Products.

Conflicts of Interest: The authors declare no conflict of interest.

\section{References}

1. Herzog, D.; Seyda, V.; Wycisk, E.; Emmelmann, C. Additive manufacturing of metals. Acta Mater. 2016, 117, 371-392. [CrossRef]

2. Trevisan, F.; Calignano, F.; Aversa, A.; Marchese, G.; Lombardi, M.; Biamino, S.; Ugues, D.; Manfredi, D. Additive manufacturing of titanium alloys in the biomedical field: Processes, properties and applications. J. Appl. Biomater. Funct. Mater. 2018, 16, 57-67. [CrossRef] [PubMed]

3. Olakanmi, E.O.; Cochrane, R.F.; Dalgarno, K.W. A review on selective laser sintering/melting (SLS/SLM) of aluminium alloy powders: Processing, microstructure, and properties. Prog. Mater. Sci. 2015, 74, 401-477. [CrossRef]

4. Zhao, H.; Debroy, T. Weld metal composition change during conduction mode laser welding of aluminum alloy 5182. Metall. Mater. Trans. B 2001, 32, 163-172. [CrossRef]

5. Trevisan, F.; Calignano, F.; Lorusso, M.; Pakkanen, J.; Aversa, A.; Ambrosio, E.; Lombardi, M.; Fino, P.; Manfredi, D. On the Selective Laser Melting (SLM) of the AlSi10Mg Alloy: Process, Microstructure, and Mechanical Properties. Materials 2017, 10, 76. [CrossRef] [PubMed]

6. Bartkowiak, K.; Ullrich, S.; Frick, T.; Schmidt, M. New Developments of Laser Processing Aluminium Alloys via Additive Manufacturing Technique. Phys. Procedia 2011, 12, 393-401. [CrossRef]

7. Louvis, E.; Fox, P.; Sutcliffe, C.J. Selective laser melting of aluminium components. J. Mater. Process. Technol. 2011, 211, 275-284. [CrossRef] 
8. Li, H.P.; Li, H.J.; Qi, L.H.; Luo, J.; Zuo, H.S. Simulation on deposition and solidification processes of $7075 \mathrm{Al}$ alloy droplets in 3D printing technology. Trans. Nonferrous Met. Soc. China 2014, 24, 1836-1843. [CrossRef]

9. Kaufmann, N.; Imran, M.; Wischeropp, T.M.; Emmelmann, C.; Siddique, S.; Walther, F. Influence of process parameters on the quality of aluminium alloy EN AW 7075 using selective laser melting (SLM). Phys. Procedia 2016, 83, 918-926. [CrossRef]

10. Qi, T.; Zhu, H.; Zhang, H.; Yin, J.; Ke, L.; Zeng, X. Selective laser melting of Al7050 powder: Melting mode transition and comparison of the characteristics between the keyhole and conduction mode. Mater. Des. 2017, 135, 257-266. [CrossRef]

11. Montero Sistiaga, M.L.; Mertens, R.; Vrancken, B.; Wang, X.; Van Hooreweder, B.; Kruth, J.P.; Van Humbeeck, J. Changing the alloy composition of Al7075 for better processability by selective laser melting. J. Mater. Process. Technol. 2016, 238, 437-445. [CrossRef]

12. Aversa, A.; Lorusso, M.; Cattano, G.; Manfredi, D.; Calignano, F.; Ambrosio, E.P.; Biamino, S.; Fino, P.; Lombardi, M.; Pavese, M. A study of the microstructure and the mechanical properties of an AlSiNi alloy produced via selective laser melting. J. Alloys Compd. 2016, 695, 1470-1478. [CrossRef]

13. Fischer, M.; Joguet, D.; Robin, G.; Peltier, L.; Laheurte, P. In situ elaboration of a binary Ti-26Nb alloy by selective laser melting of elemental titanium and niobium mixed powders. Mater. Sci. Eng. C 2016, 62, 852-859. [CrossRef] [PubMed]

14. Martin, J.H.; Yahata, B.D.; Hundley, J.M.; Mayer, J.A.; Schaedler, T.A.; Pollock, T.M. 3D printing of high-strength aluminium alloys. Nature 2017, 549, 365-369. [CrossRef] [PubMed]

15. Aversa, A.; Marchese, G.; Lorusso, M.; Calignano, F.; Biamino, S.; Ambrosio, E.P.; Manfredi, D.; Fino, P.; Lombardi, M.; Pavese, M. Microstructural and Mechanical Characterization of Aluminum Matrix Composites Produced by Laser Powder Bed Fusion. Adv. Eng. Mater. 2017, 19, 1700180. [CrossRef]

16. Aversa, A.; Science, A.; Torino, P.; Duca, C. Microstructural and Mechanical Properties of Al-Si-Ni alloy Produced by Direct Metal Laser Sintering. In Proceedings of the WorldPM 2016 Congress, Hamburg, Germany, 9-13 October 2016.

17. Aversa, A.; Pavese, M.; Biamino, S.; Manfredi, D.; Ambrosio, E.; Calignano, F.; Badini, C.; Fino, P. Produzione di Leghe 7000 con DMLS Direct Metal Laser Sintering di Leghe Alluminio-Zinco-Magnesio. Aim. 2014 Lecce 2014. Available online: http:/ / www.aimat2014.unisalento.it/wp-content/uploads/2014/09/Sessioniposter_AIMAT_ver-4.pdf (accessed on 25 April 2018).

18. Manfredi, D.; Calignano, F.; Krishnan, M.; Canali, R.; Ambrosio, E.P.; Biamino, S.; Ugues, D.; Pavese, M.; Fino, P. Additive Manufacturing of Al Alloys and Aluminium Matrix Composites (AMCs). Light Met. Alloy Appl. 2014, 3-34. [CrossRef]

19. Kruth, J.P.; Froyen, L.; Van Vaerenbergh, J.; Mercelis, P.; Rombouts, M.; Lauwers, B. Selective laser melting of iron-based powder. J. Mater. Process. Technol. 2004, 149, 616-622. [CrossRef]

20. Gu, D.; Wang, H.; Dai, D.; Chang, F.; Meiners, W.; Hagedorn, Y.-C.; Wissenbach, K.; Kelbassa, I.; Poprawe, R. Densification behavior, microstructure evolution, and wear property of TiC nanoparticle reinforced AlSi10Mg bulk-form nanocomposites prepared by selective laser melting. J. Laser Appl. 2015, 27, S17003. [CrossRef]

21. Abachi, P.; Naseri, P.S.Z.; Purazrang, K.; Coyle, T.W. Fracture Behavior Evaluation of High-Strength 7050 Fracture Behavior Evaluation of High-Strength 7050 and 7075 Aluminum Alloys Using V-Notched Specimen and 7075 Aluminum Alloys Using V-Notched Specimen. In Fracture Mechanics-Properties, Patterns and Behaviours; Alves, L., Ed.; InTech: Houston, TX, USA, 2016. [CrossRef]

22. Naimi, A.; Yousfi, H.; Trari, M. Influence of cold rolling degree and ageing treatments on the precipitation hardening of 2024 and 7075 alloys. Mech. Time-Depend. Mater. 2012, 17, 285-296. [CrossRef]

23. Read, N.; Wang, W.; Essa, K.; Attallah, M.M. Selective laser melting of AlSi10Mg alloy: Process optimisation and mechanical properties development. Mater. Des. 2015, 65, 417-424. [CrossRef]

24. Wu, J.; Wang, X.Q.; Wang, W.; Attallah, M.M.; Loretto, M.H. Microstructure and strength of selectively laser melted AlSi10Mg. Acta Mater. 2016, 117, 311-320. [CrossRef]

25. Marchese, G.; Aversa, A.; Lorusso, M.; Manfredi, D.; Calignano, F.; Lombardi, M.; Biamino, S.; Pavese, M. Development and Characterisation of Aluminium Matrix Nanocomposites AlSi10Mg/ $\mathrm{MgAl}_{2} \mathrm{O}_{4}$ by Laser Powder Bed Fusion. Metals 2018, 8, 175. [CrossRef] 
26. Schmidtke, K.; Palm, F.; Hawkins, A.; Emmelmann, C. Process and Mechanical Properties: Applicability of a Scandium modified Al-alloy for Laser Additive Manufacturing. Phys. Procedia 2011, 12, 369-374. [CrossRef]

27. Aversa, A.; Lorusso, M.; Trevisan, F.; Ambrosio, E.; Calignano, F.; Manfredi, D.; Biamino, S.; Fino, P.; Lombardi, M.; Pavese, M. Effect of Process and Post-Process Conditions on the Mechanical Properties of an A357 Alloy Produced via Laser Powder Bed Fusion. Metals 2017, 7, 68. [CrossRef] 